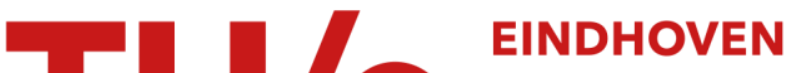

\section{Shape characterization of polymersome morphologies via light scattering techniques}

\section{Citation for published version (APA):}

Abdelmohsen, L. K. E. A., Rikken, R. S. M., Christianen, P. C. M., van Hest, J. C. M., \& Wilson, D. A. (2016). Shape characterization of polymersome morphologies via light scattering techniques. Polymer, 107, 445-449. https://doi.org/10.1016/j.polymer.2016.06.067

\section{Document license:}

TAVERNE

DOI:

10.1016/j.polymer.2016.06.067

Document status and date:

Published: 19/12/2016

\section{Document Version:}

Publisher's PDF, also known as Version of Record (includes final page, issue and volume numbers)

\section{Please check the document version of this publication:}

- A submitted manuscript is the version of the article upon submission and before peer-review. There can be important differences between the submitted version and the official published version of record. People interested in the research are advised to contact the author for the final version of the publication, or visit the $\mathrm{DOI}$ to the publisher's website.

- The final author version and the galley proof are versions of the publication after peer review.

- The final published version features the final layout of the paper including the volume, issue and page numbers.

Link to publication

\section{General rights}

Copyright and moral rights for the publications made accessible in the public portal are retained by the authors and/or other copyright owners and it is a condition of accessing publications that users recognise and abide by the legal requirements associated with these rights.

- Users may download and print one copy of any publication from the public portal for the purpose of private study or research.

- You may not further distribute the material or use it for any profit-making activity or commercial gain

- You may freely distribute the URL identifying the publication in the public portal.

If the publication is distributed under the terms of Article $25 \mathrm{fa}$ of the Dutch Copyright Act, indicated by the "Taverne" license above, please follow below link for the End User Agreement:

www.tue.nl/taverne

Take down policy

If you believe that this document breaches copyright please contact us at:

openaccess@tue.nl

providing details and we will investigate your claim. 


\title{
Shape characterization of polymersome morphologies via light scattering techniques
}

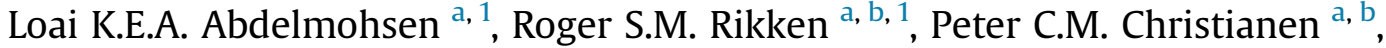 \\ Jan C.M. van Hest ${ }^{\text {a, }}{ }^{*}$, Daniela A. Wilson ${ }^{\text {a, }}{ }^{* *}$ \\ ${ }^{a}$ Radboud University, Institute for Molecules and Materials, Heyendaalseweg 135, 6525 AJ, Nijmegen, The Netherlands \\ ${ }^{\mathrm{b}}$ Radboud University, High Field Magnet Laboratory (HFML-EMFL), Toernooiveld 7, 6525 ED, Nijmegen, The Netherlands
}

\section{A R T I C L E I N F O}

Article history:

Received 13 May 2016

Received in revised form

24 June 2016

Accepted 28 June 2016

Available online 30 June 2016

Keywords:

Polymersomes

Morphology

Asymmetric flow field flow fractionation

\begin{abstract}
A B S T R A C T
Polymersomes, vesicles self-assembled from amphiphilic block copolymers, are well known for their robustness and for their broad applicability. Generating polymersomes of different shape is a topic of recent attention, specifically in the field of biomedical applications. To obtain information about their exact shape, tomography based on cryo-electron microscopy is usually the most preferred technique. Unfortunately, this technique is rather time consuming and expensive. Here we demonstrate an alternative analytical approach for the characterization of differently shaped polymersomes such as spheres, prolates and discs via the combination of multi-angle light scattering (MALS) and quasi-elastic light scattering (QELS). The use of these coupled techniques allowed for accurate determination of both the radius of gyration $\left(R_{g}\right)$ and the hydrodynamic radius $\left(R_{h}\right)$. This afforded us to determine the shape ratio $\rho$ $\left(R_{g} / R_{h}\right)$ with which we were able to distinguish between polymersome spheres, discs and rods.
\end{abstract}

(c) 2016 Elsevier Ltd. All rights reserved.

\section{Introduction}

Numerous biomedical applications that involve interaction between cells and particles are greatly affected by chemophysical properties such as particle size, surface chemistry and shape [1-3]. This latter property is more difficult to control than the other features, which therefore led until recently to an underrepresentation of publications on shape effects in particle-cell interactions in the nanomedicine field. The importance of shape is nowadays well recognized and also different approaches have been reported, such as the PRINT technology [4-7] and particle stretch techniques [8,9]. Bottom-up self-assembly of polymersomes with various shapes is another emerging technique [2,10]. Polymersomes are assembled from synthetic block copolymers containing hydrophobic and hydrophilic blocks [11], which can be chemically modified to offer functionality either on the surface or in the membrane bilayer $[12,13]$. In addition, the shape of these polymersomes can be transformed into a large array of morphologies [14-16]. In general,

\footnotetext{
* Corresponding author.

** Corresponding author.

E-mail addresses: j.vanhest@science.ru.nl (J.C.M. van Hest), d.wilson@science.ru. nl (D.A. Wilson).

1 These authors contributed equally to this work.
}

vesicles can change shape from an initially spherical morphology via two possible routes: deflation via oblates (discs) or deflation via prolates (rods) as is shown in Fig. 1 [17].

In order to gain more information about the shape of the formed structures, dry and cryo-electron microscopy techniques, both in scanning (SEM) and transmission (TEM) mode, are the method of choice [18]. In some cases differentiation between different morphologies (e.g. discs and spheres) can be rather difficult and misleading and therefore, multi angle tomography imaging has to be performed on these structures to obtain an accurate geometrical understanding. Unfortunately, these techniques are rather expensive, not accessible to everyone and also time consuming, as sample preparation requires long waiting times. It would therefore be advantageous to have access to a shape characterization technique, which is robust, fast and does not require extensive sample preparation.

An attractive method for polymersome shape analysis that we propose is the combination of asymmetric flow field flow fractionation (AF4), coupled with static light scattering (MALS) and dynamic light scattering detectors (QELS). AF4 is necessary for the fractionation of the sample components prior to detection, which enables the collection of informative data from monodisperse particles instead of the whole sample population [19,20]. MALS furthermore provides information regarding the radius of gyration 


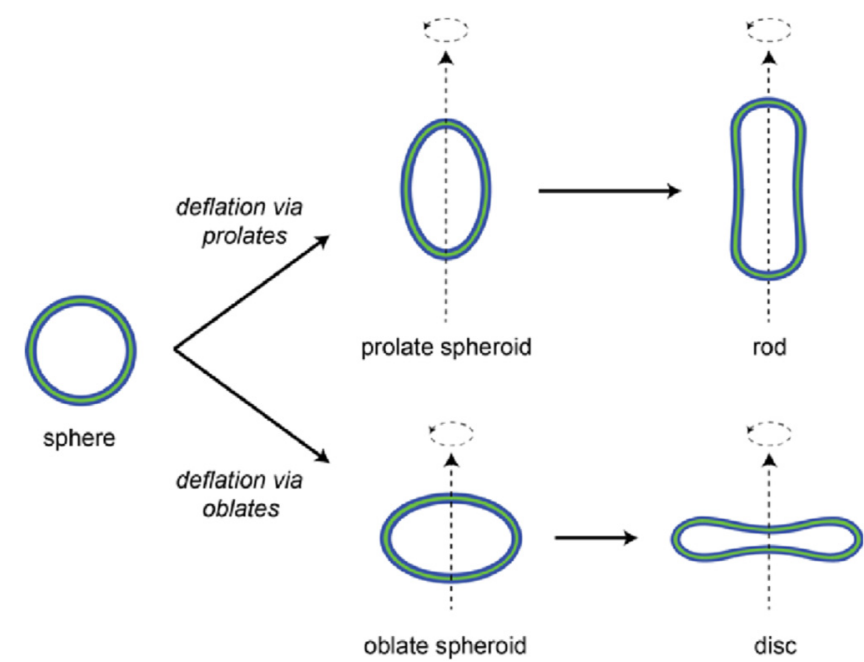

Fig. 1. Schematic illustration showing the two possible deflation paths of a spherical polymersome. Deflation occurs either via the prolates (prolate spheroids and rods) or oblates (oblate spheroids and discs). All shapes are cylindrically symmetric, with the axis of symmetry given by the dashed arrows.

$\left(R_{g}\right)$, also known as the root-mean-square radius (rms) while the hydrodynamic radius $\left(R_{h}\right)$ is determined by using QELS. The ratio of the two radii gives a shape ratio, $\rho$, which is specific to the particle morphology [21-26]. The combination of AF4-MALS-QELS was previously used to characterize several morphologies of polymer aggregates, in particular micelles [27-30]. The use of this technique to characterize the shapes of different polymer vesicles has been overlooked so far. Till et al. showed that this technique is also valuable for the analysis of polymersomes assembled from different polymer types and lengths [31]. Shape ratios for polymersomes could however only be determined for spheres, but not for other morphologies. To the best of our knowledge this is the first and only example to use this technique on various polymeric vesicles for shape analysis. Herein we report how AF4-MALS-QELS can be used as a generic method for the characterization of different poly (ethylene glycol)-b-poly(styrene) (PEG-PS) based polymersome morphologies (spheres, discs and rods).

\section{Materials and methods}

All chemicals were used as received unless otherwise stated. Styrene was distilled before polymerization to remove the inhibitor. $\mathrm{CuBr}$, prior to use, was washed using glacial acetic acid, ethanol and diethylether and left to dry under vacuum. Anisole and $N, N, N^{\prime}$, $N^{\prime \prime}, \quad N^{\prime \prime}$-pentamethyl-diethylenetriamine (PMDETA) were purchased from Sigma Aldrich. For the self assembly, polymer was dissolved in tetrahydrofuran (HPLC grade) and 1,4 dioxane (HPLC grade), which were purchased from Biosolve B.V. Ultra-pure MilliQ water that was used for the self-assembly was obtained from a Labconco Water Pro PS purification system (18.2 M $\Omega$ ). Sodium nitrate used for preparing the AF4 eluent was purchased from Merck.

Poly(ethylene glycol)-polystyrene $\left(\mathrm{PEG}_{\mathrm{n}}-\mathrm{PS}_{\mathrm{m}}\right)$ was synthesized by atom-transfer radical polymerization (ATRP) starting from PEGmacro initiators as described previously [32] yielding $\mathrm{PEG}_{44}-\mathrm{PS}_{133}$ polymers with $\mathrm{a} \boxminus=1.06$ and $\mathrm{M}_{\mathrm{n}}=16.0 \mathrm{~kg} \mathrm{~mol}^{-1}$.

Sample preparation was performed by dissolving $10 \mathrm{mg}$ of $\mathrm{PEG}_{44}-\mathrm{PS}_{133}$ in a 2:3 ( $\mathrm{vol} / \mathrm{vol}$ ) mixture of 1,4-dioxane and THF while stirring at $750 \mathrm{rpm}$. Water was added by a syringe pump at a rate of $1 \mathrm{~mL} \mathrm{~h}^{-1}$ (under constant stirring) until the final volume of the solution reached $4 \mathrm{~mL}$ [33]. Self-assembly always occurred when the water content reached a value of about $20 \%$ (vol), which was noticeable by sample becoming cloudy.

To create spherical polymersomes, the polymers were initially dissolved in $1 \mathrm{~mL}$ of organic solvent mixture after which $3 \mathrm{~mL}$ of water was added. Immediately after sample preparation, an aliquot of sample was kinetically trapped by injecting it into an excess of water. To create disc-shaped polymersomes, the polymers were dissolved in $1.33 \mathrm{~mL}$ of organic solvent mixture and $2.66 \mathrm{~mL}$ of water was added. Self-assembly occurred after the addition of $0.33 \mathrm{~mL}$ of water. The remaining $2.33 \mathrm{~mL}$ of water was added after self-assembly, which led to a difference in solvent composition (osmotic pressure) between the polymersome interior and exterior. Afterwards, the sample was left to stand to equilibrate over 1 day during which time the polymersomes deflated into discs, to relieve the osmotic pressure. An aliquot of this sample was quenched by injecting it in an excess of water. To create rod-shaped polymersomes, the polymers were dissolved in $2 \mathrm{~mL}$ of organic solvent mixture and $2 \mathrm{~mL}$ of water was added. Self-assembly occurred after the addition of $0.5 \mathrm{~mL}$ of water. The remaining $1.5 \mathrm{~mL}$ of water was added after self-assembly which, this time, led to a smaller difference in solvent composition (osmotic pressure) between the polymersome interior and exterior. The sample was left to stand for 3 days during which the polymersomes deflated into rods, to relieve the osmotic pressure. At that time, an aliquot was kinetically trapped by injecting it into an excess of water. Only the kinetically trapped samples were used for TEM, cryo-TEM and AF4-QELS-MALS.

\subsection{Proton nuclear resonance}

A Varian Inova 400 was used to record the ${ }^{1} \mathrm{HNMR}$ spectra of the block copolymer. $\mathrm{CDCl}_{3}$ was used as solvent and TMS as an internal standard.

\subsection{Gel permeation chromatography}

A Shimadzu Prominence GPC system equipped with a PL gel $5 \mu \mathrm{m}$ mixed D column (Polymer Laboratories) and differential refractive index and UV (254 nm) detectors was used to determine the molecular weight and $Ð$ of the block-copolymer. Calibration was performed by using polystyrene standards in the range of 580 to $377,400 \mathrm{~g} \mathrm{~mol}^{-1}$. THF was used as eluent with a flow rate of $1 \mathrm{~mL} \mathrm{~min}^{-1}$.

\subsection{Transmission electron microscopy}

A JEOL 1010 microscope equipped with a CCD camera at an acceleration voltage of $60 \mathrm{kV}$ was used to image the formed morphologies. Samples were prepared by placing $5 \mu \mathrm{L}$ of the solution on a carbon-coated $\mathrm{Cu}$ grid (200 mesh, EM science) which were allowed to air-dry for at least $24 \mathrm{~h}$. Processing and analysis of TEM images was performed using Image software, a program developed by the NIH and available as public domain software at http:// rsbweb.nih.gov/ij/.

\subsection{Cryogenic transmission microscopy}

The cryogenic transmission electron microscopy (Cryo-TEM) experiments were performed on a JEOL TEM 2100 microscope (JEOL, Japan) and processed and analyzed using ImageJ software.

\subsection{AF4-UV-MALS-QELS}

The asymmetric flow field flow fractionation - UV - multi angle light scattering - quasi light scattering (AF4-UV-MALS-QELS) experiments were performed using a Wyatt Eclipse AF4 instrument with a short channel equipped with a regenerated cellulose (RC) $10 \mathrm{kDa}$ membrane (Millipore) and spacer of $350 \mu \mathrm{m}$. The channel 
was linked to a Shimadzu LC-20A Prominence system with Shimadzu CTO20A injector. The following detectors were connected to the AF4 system: a Shimadzu SPD20A UV detector; a Wyatt DAWN HELEOS II light scattering detector (MALS) installed at various angles $\left(12.9^{\circ}, 20.6^{\circ}, 29.6^{\circ}, 37.4^{\circ}, 44.8^{\circ}, 53.0^{\circ}, 61.1^{\circ}, 70.1^{\circ}, 80.1^{\circ}, 90.0^{\circ}\right.$, $99.9^{\circ}, 109.9^{\circ}, 120.1^{\circ}, 130.5^{\circ}, 149.1^{\circ}$, and $157.8^{\circ}$ ) operated with a $664.5 \mathrm{~nm}$ laser; a QELS detector installed at an angle of $140.1^{\circ}$ and a Wyatt Optilab Rex refractive index detector. Prior to the measurements detectors were normalized using Bovine Serum Albumin. The AF4 channel was pre-washed with running solution of $5 \mathrm{mM}$ $\mathrm{NaNO}_{3}$. This solution was also used as eluent. The processing and analysis of the $R_{g}$ and the $R_{h}$ data were performed using Astra 6.1.1. The exact methods used are available in the Supplementary Tables 1 and 2

\section{Results and discussions}

\subsection{Theoretical approximation of $R_{g} / R_{h}$}

The dimensions of particles can be described by the hydrodynamic radius $\left(R_{h}\right)$ and the radius of gyration $\left(R_{g}\right) . R_{h}$ is the radius of a hard sphere in solution and it is described via equation [20,34,35].

$R_{h}=\frac{k T}{6 \pi \eta D}$

with $k$ the Boltzmann constant, $T$ the temperature, $\eta$ the viscosity of the solvent and $D$ the diffusion coefficient of the polymersome. $R_{g}$ is an angular dependent value that can be defined as the root mean square distance between mass and their common center and it can be calculated by [36].

$R_{g}^{2}=\frac{1}{V} \oint r^{2} \cdot d V$

with $V$ the volume of the scattering part of the polymersome and $r$ the distance between the center of mass and an infinitesimal small scattering volume element. The combination of $R_{g}$ and $R_{h}$ allows the shape dependent factor $\rho\left(=R_{g} / R_{h}\right)$ to be calculated in order to distinguish between spheres, discs and rods [34,37,38].

Polymersomes are filled with and surrounded by solvents, which do not scatter light. The only part of the polymersomes that does scatter light is the PEG-PS membrane itself. By definition, the polymersome membrane is located at the surface of the vesicle and therefore only the polymersome membrane contributes to $R_{g}$. Therefore, equation (2) becomes:

$R_{g}^{2}=\frac{1}{A} \oint r^{2} \cdot d A$

For a spherical polymersome, all the scattering mass is concentrated on the surface of the sphere, at radius $R$. The hydrodynamic radius of a sphere is by definition always equal to the outer radius $R$ and therefore $R_{g} / R_{h}=1$ [39]. The expected value of $R_{g} / R_{h}$ for a hollow rod or a hollow disc is however more complicated since it also depends on the aspect ratio and the exact shape. Over the last years, equations for calculating the $R_{h}$ of rods and discs have been formulated [35,36,38,40-42]. However, the equations for discs are mostly valid for solid toroidal discs (like micellar discs) and do not apply to hollow biconcave discs $[35,36,42]$. The expressions for rods are furthermore only valid for large aspect ratios $[38,40,41]$ (supplementary information 1 and Supplementary Fig. 1). Our polymersome rods and discs have a relatively low aspect ratio, in the order of $2-4$. Therefore, we have chosen to use the equations of Perrin for oblate and prolate spheroids as an approximation $[38,43]$, which are especially valid in the low aspect ratio regime. Using these equations we calculated $R_{h}$ as a function of the aspect ratio. The corresponding value of $R_{g}$ was obtained by numerically calculating the integral given in equation (3) over the surface of both oblate and prolate hollow spheroids (supplementary information 1 and Supplementary Fig. 2). The calculated values of $R_{g} / R_{h}$ are shown in Fig. 2.

For both rods and discs, the value of $R_{g} / R_{h}$ is expected to be larger than that of spheres. The increase in $R_{g} / R_{h}$ with increasing aspect ratio is expected to be largest for the prolates.

\subsection{Experimental shape analysis via AF4-MALS-QELS}

We started by confirming the morphologies of the three different polymersome samples using TEM and (multi angle) cryoTEM imaging techniques (Fig. 3 and Supplementary Fig. 3). Moreover, batch DLS was used to confirm both the sizes and the relative small poly dispersity of the structures (Supplementary Fig. 4).

Having confirmed the final morphologies of these PEG-PS polymersomes, we continued to investigate whether their experimentally measured dimensionless shape parameter $\rho\left(R_{g} / R_{h}\right)$ would match their expected theoretical values. Aliquots of the samples with different morphologies were injected into the AF4 system and the flow program was optimized to obtain high-resolution peaks and high particle count (supplementary information 2.2). Spherical polymersomes were analyzed after the AF4 run and no change in shape was observed (Supplementary Fig. 5). This was to be expected due to the glassy nature of PS based polymersomes. Via thorough analysis of the acquired light scattering data, information about the colloidal radii $R_{g}$ and $R_{h}$ was obtained, while the ratio of $R_{g} / R_{h}$ provided information about the shape (Fig. 4).

We first started by measuring spherical polymersome samples. Analysis of their light scattering data resulted as expected in an average $R_{g}$ almost equal to the measured $R_{\mathrm{h}}$, leading to an $R_{g} / R_{h}$ of $1.01 \pm 0.04$ (Fig. 4d and Supplementary Fig. 9), which is in agreement with the theoretical hollow sphere shape ratio. The light scattering data of the discs showed a relatively high $R_{g}$ value compared to the $R_{h}$ which resulted in an $R_{g} / R_{h}$ of $1.20 \pm 0.07$ (Fig. $4 \mathrm{~d}$ and Supplementary Fig. 10), referring to disc-like structures (Fig. 2). The light scattering data of the prolate samples revealed a considerably larger average $R_{g}$ in comparison with the $R_{h}$ value. This

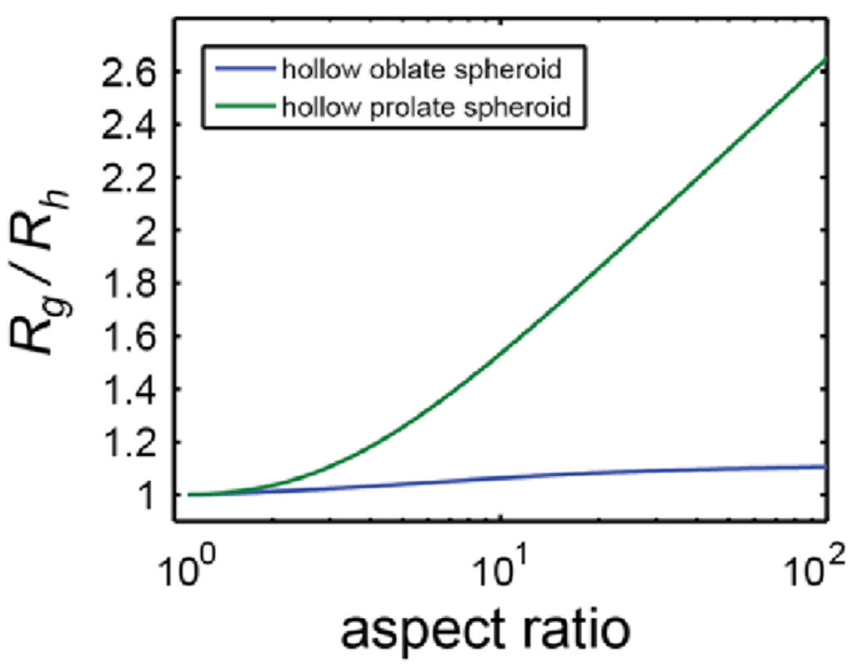

Fig. 2. Theoretical expected values of $R_{g} / R_{h}$ for hollow oblate spheroids and hollow prolate spheroids as function of the aspect ratio. For an aspect ratio of 1 , both the prolates and the oblates represent a sphere and thus $R_{g} / R_{h}$ starts at 1 . For both oblates and prolates, the value of $R_{g} / R_{h}$ increases with increasing aspect ratio, although the effect is much larger for the prolates. 


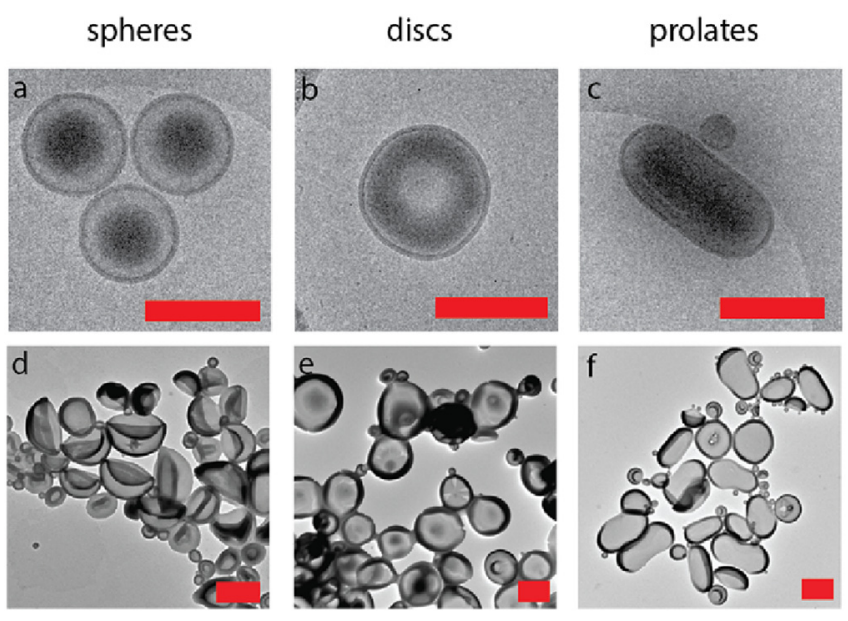

Fig. 3. Cryo-TEM (a, b and c) and dry-TEM images (d, e and f) of spheres (a, d), discs (b,e) and prolates (rods) (c,f). All scale bars are $500 \mathrm{~nm}$. The spheres in the dry-TEM image are collapsed due to drying effects but the cryo-TEM image clearly proves the spherical morphology. The discs have a different intensity distribution than spheres in cryo-TEM but in dry-TEM the differences are much more clear. The rods are very well recognizable in both cryo-TEM and TEM. Angle dependent cryo-TEM for all three morphologies is shown in Supplementary Fig. 3.

large difference led to an $R_{g} / R_{h}$ of $1.64 \pm 0.15$ (Fig. $4 \mathrm{~d}$ and Supplementary Fig. 11). The experimental data shows indeed that the rods and the discs have a higher $R_{g} / R_{h}$ than spheres as was predicted, with that of the rods being the largest. This trend is in agreement with the theoretical predictions in Fig. 2. However a quantitative match between the experimental data with the predictions is not observed (Supplementary Fig. 12), which can be attributed to the differences in mass distribution between discs or rods, and the theoretical oblate or prolate spheroids, which would alter $R_{g}$. As there are currently no exact expressions for $R_{h}$ for hollow rods and hollow biconcave discs of low aspect ratio these deviations are to be expected. Nevertheless, we have proven that it is certainly possible to distinguish between spherical, rod-shaped and disc-shaped polymersomes based on the measured $R_{g} / R_{h}$ values alone, since these values and their spreads are all in different regimes and do not overlap.

\section{Conclusion}

In summary, we have shown that spherical, disc-shaped and rod-shaped PEG-PS polymersomes can be distinguished by measuring their hydrodynamic radius and radius of gyration simultaneously. The values of $R_{g} / R_{h}$ that were obtained experimentally for the three different shapes differ significantly, with the highest value observed for rods and the lowest for spheres, which is in accordance with theoretical predictions based on prolate and oblate spheroids. We therefore see great potential in employing the combination of multi angle and quasi-elastic light scattering in the research on polymersome shape changes. We expect that with the development of good expressions for $R_{h}$ for polymersome discs and rods of low aspect ratio, the MALS-QELS combination could not only be used to experimentally distinguish between those shapes but also to obtain their aspect ratios. Furthermore, we are confident a)

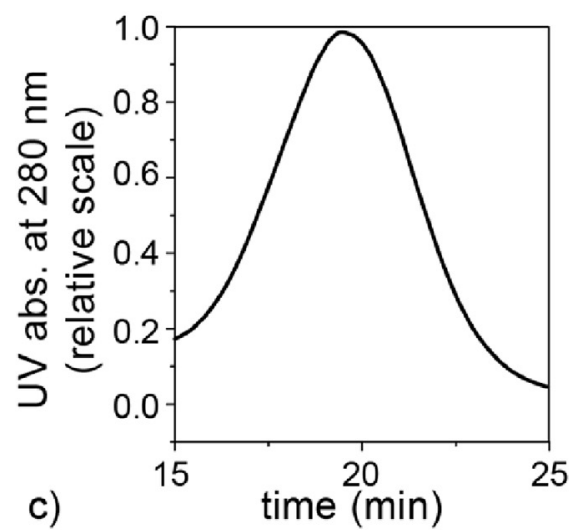

c)

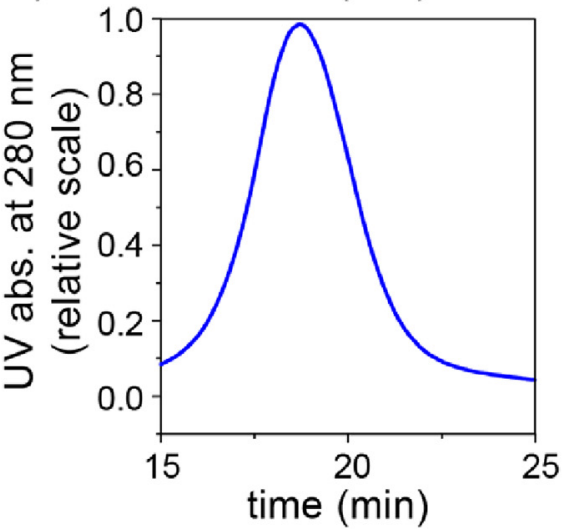

b)
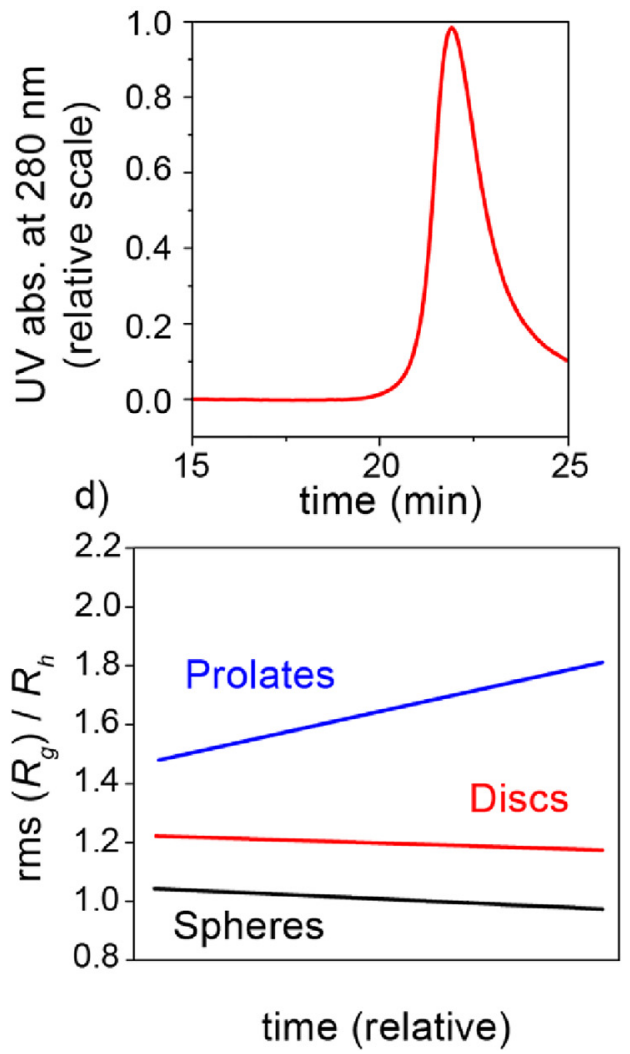

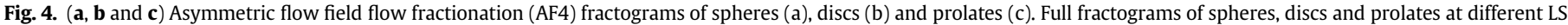

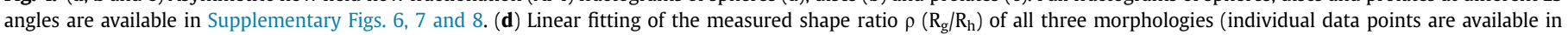
Supplementary Fig. 9, 10 and 11). 
that the combination of MALS and QELS will prove to be very useful for shape characterization of a wide variety of other polymeric assemblies in both academia and industry.

\section{Acknowledgements}

This work was supported by the European Research Council under the European Union's Seventh Framework Programme (FP7/ 2007-20012)/ERC-StG 307679 "StomaMotors". Authors acknowledge support from the Ministry of Education, Culture and Science (Gravitation program 024.001.035). R.S.M.R. acknowledges the Graduate School for Molecules and Materials for a $\mathrm{PhD}$ position and NWO for its corresponding funding. We acknowledge the support of HFML-RU/FOM, member of the European Magnetic Field Laboratory (EMFL). Finally, we would like to thank Geert-Jan Janssen for his assistance with the Cryo-TEM imaging.

\section{Appendix A. Supplementary data}

Supplementary data related to this article can be found at http:// dx.doi.org/10.1016/j.polymer.2016.06.067.

\section{References}

[1] A.E Nel, L Madler, D Velegol, T, Xia, E.M.V. Hoek, P. Somasundaran, F. Klaessig, V. Castranova, M. Thompson, Understanding biophysicochemical interactions at the nano-bio interface, Nat. Mater. 8 (2009) 543-557.

[2] L. Wang, G.H. Liu, X.R. Wang, J.M. Hu, G.Y. Zhang, S.Y. Liu, Acid-disintegratable polymersomes of ph-responsive amphiphilic diblock copolymers for intracellular drug delivery, Macromolecules 48 (2015) 7262-7272.

[3] J.H. Park, G. von Maltzahn, L.L. Zhang, A.M. Derfus, D. Simberg, T.J. Harris, E. Ruoslahti, S.N. Bhatia, M.J. Sailor, Systematic surface engineering of magnetic nanoworms for in vivo tumor targeting, Small 5 (2009) 694-700.

[4] J.P. Rolland, B.W. Maynor, L.E. Euliss, A.E. Exner, G.M. Denison, J.M. DeSimone Direct fabrication and harvesting of monodisperse, shape-specific nano-biomaterials, J. Am. Chem. Soc. 127 (2005) 10096-10100.

[5] S.E.A. Gratton, M.E. Napier, P.A. Ropp, S.M. Tian, J.M. DeSimone, Microfabricated particles for engineered drug therapies: elucidation into the mechanisms of cellular internalization of PRINT particles, Pharm. Res. 25 (2008) 2845-2852.

[6] S.E.A. Gratton, P.A. Ropp, P.D. Pohlhaus, J.C. Luft, V.J. Madden, M.E. Napier, J.M. DeSimone, The effect of particle design on cellular internalization pathways, Proc. Natl. Acad. Sci. 105 (2008) 11613-11618.

[7] K.G. Reuter, J.L. Perry, D. Kim, J.C. Luft, R.H. Liu, J.M. DeSimone, Targeted PRINT hydrogels: the role of nanoparticle size and ligand density on cell association, biodistribution, and tumor accumulation, Nano Lett 15 (2015) 6371-6378.

[8] J.A. Champion, Y.K. Katare, S. Mitragotri, Making polymeric micro- and nanoparticles of complex shapes, Proc. Natl. Acad. Sci. 104 (2007) 11901-11904.

[9] X.J. Zan, A. Garapaty, J.A. Champion, Engineering polyelectrolyte capsules with independently controlled size and shape, Langmuir 31 (2015) 7601-7608.

[10] J. Thevenot, H. de Oliveira, O. Sandre, L. Pourtau, E. Andres, S. Miraux E. Thiaudiere, E. Berra, S. Lecommandoux, Multifunctional polymersomes for Cancer theranostics, J. Control. Release 172 (2013) E44-E45.

[11] B.M. Discher, Y.Y. Won, D.S. Ege, J.C.M. Lee, F.S. Bates, D.E. Discher D.A. Hammer, Polymersomes: tough vesicles made from diblock copolymers, Science 284 (1999) 1143-1146.

[12] M.C.M. van Oers, L.K.E.A. Abdelmohsen, F.P.J.T. Rutjes, J.C.M. van Hest, Aqueous asymmetric cyclopropanation reactions in polymersome membranes, Chem. Commun. 50 (2014) 4040-4043.

[13] S.A. Meeuwissen, M.F. Debets, J.C.M. van Hest, Copper-free click chemistry on polymersomes: pre- vs. Post-Self-Assembly functionalisation, Polym. Chem. 3 (2012) 1783-1795.

[14] R. Salva, J.F. Le Meins, O. Sandre, A. Brulet, M. Schmutz, P. Guenoun, S. Lecommandoux, Polymersome shape transformation at the nanoscale, Acs Nano 7 (2013) 9298-9311.

[15] J.D. Robertson, G. Yealland, M. Avila-Olias, L. Chierico, O. Bandmann, S.A. Renshaw, G. Battaglia, pH-sensitive tubular polymersomes: formation and applications in cellular delivery, Acs Nano 8 (2014) 4650-4661.

[16] S.A. Meeuwissen, K.T. Kim, Y.C. Chen, D.J. Pochan, J.C.M. van Hest, Controlled shape transformation of polymersome stomatocytes, Angew. Chem. Int. Ed. 50 (2011) 7070-7073.

[17] U. Seifert, K. Berndl, R. Lipowsky, Shape transformations of vesicles - phasediagram for spontaneous-curvature and bilayer-coupling models, Phys. Rev. A 44 (1991) 1182-1202.

[18] L.K.E.A. Abdelmohsen, M. Nijemeisland, G.M. Pawar, G.J.A. Janssen, R.J.M. Nolte, J.C.M. van Hest, D.A. Wilson, Dynamic loading and unloading of proteins in polymeric stomatocytes: formation of an enzyme-loaded supramolecular nanomotor, Acs Nano 10 (2016) 2652-2660.

[19] J. Gigault, J.M. Pettibone, C. Schmitt, V.A. Hackley, Rational strategy for characterization of nanoscale particles by asymmetric- flow field flow fractionation: a tutorial, Anal. Chim. Acta 809 (2014) 9-24.

[20] L. Pitkanen, A.M. Striegel, AF4/MALS/QELS/DRI characterization of regular star polymers and their 'span analogs, Analyst 139 (2014) 5843-5851.

[21] W. Burchard, Solution properties of branched macromolecules, Adv. Polym. Sci. 143 (1999) 113-194.

[22] L. Nilsson, Separation and characterization of food macromolecules using field-flow fractionation: a review, Food Hydrocoll. 30 (2013) 1-11.

[23] S. Boye, F. Ennen, L. Scharfenberg, D. Appelhans, L. Nilsson, A. Lederer, From 1D rods to 3D networks: a biohybrid topological diversity investigated by asymmetrical flow field-flow fractionation, Macromolecules 48 (2015) 4607-4619.

[24] A. Lederer, S. Boye, Asymmetrical flow field flow fractionation for investigating intermolecular interactions of multifunctional polymers, Lc•Gc Eur. 24 (2011) 620.

[25] F. Ennen, P. Fenner, S. Boye, A. Lederer, H. Komber, B. Voit, D. Appelhans, Sphere-like protein-glycopolymer nanostructures tailored by polyassociation, Biomacromolecules 17 (2016) 32-45.

[26] R.P. Nze, T. Nicolai, C. Chassenieux, E. Nicol, S. Boye, A. Lederer, Effect of connectivity on the structure and the liquid-solid transition of dense suspensions of soft colloids, Macromolecules 48 (2015) 7995-8002.

[27] M.A. Awan, V.L. Dimonie, D. OuYang, M.S. ElAasser, Solution properties of diblock copolymers of polystyrene-block-polybutadiene, Langmuir 13 (1997) $140-146$.

[28] J. Ehrhart, A.F. Mingotaud, F. Violleau, Asymmetrical flow field-flow fractionation with multi-angle light scattering and quasi elastic light scattering for characterization of poly(ethyleneglycol-b-epsilon-caprolactone) block copolymer self-assemblies used as drug carriers for photodynamic therapy, J. Chromatogr. A 1218 (2011) 4249-4256.

[29] T. Miller, R. Rachel, A. Besheer, S. Uezguen, M. Weigandt, A. Goepferich, Comparative investigations on in vitro Serum stability of polymeric micelle formulations, Pharm. Res. 29 (2012) 448-459.

[30] M. Wagner, M.J. Barthel, R.R.A. Freund, S. Hoeppener, A. Traeger, F.H. Schacher, U.S. Schubert, Solution self-assembly of poly(ethylene oxide)Block-Poly(furfuryl glycidyl ether)-Block-Poly(allyl glycidyl ether) based triblock terpolymers: a field-flow fractionation study, Polym. Chem. 5 (2014) 6943-6956.

[31] U. Till, M. Gaucher-Delmas, P. Saint-Aguet, G. Hamon, J.D. Marty, C. Chassenieux, B. Payre, D. Goudouneche, A.F. Mingotaud, F. Violleau, Asymmetrical flow field-flow fractionation with multi-angle light scattering and quasi-elastic light scattering for characterization of polymersomes: comparison with classical techniques, Anal. Bioanal. Chem. 406 (2014) $7841-7853$

[32] K.T. Kim, J.H. Zhu, S.A. Meeuwissen, J.J.L.M. Cornelissen, D.J. Pochan, R.J.M. Nolte, J.C.M. van Hest, Polymersome stomatocytes: controlled shape transformation in polymer vesicles, J. Am. Chem. Soc. 132 (2010) $12522-12524$

[33] R.S.M. Rikken, H.H.M. Kerkenaar, R.J.M. Nolte, J.C. Maan, J.C.M. van Hest, P.C.M. Christianen, D.A. Wilson, Probing morphological changes in polymersomes with magnetic birefringence, Chem. Commun. 50 (2014) 5394-5396.

[34] A.K. Brewer, A.M. Striegel, Characterizing the size, shape, and compactness of a polydisperse prolate ellipsoidal particle via quadruple-detector hydrodynamic chromatography, Analyst 136 (2011) 515-519.

[35] S.U. Egelhaaf, P. Schurtenberger, Shape transformations in the lecithin bilesalt system - from cylinders to vesicles, J. Phys. Chem. 98 (1994) 8560-8573.

[36] S.E. Anachkov, P.A. Kralchevsky, K.D. Danov, G.S. Georgieva, K.P. Ananthapadmanabhan, Disclike vs. Cylindrical micelles: generalized model of micelle growth and data interpretation, J. Colloid. Interf. Sci. 416 (2014) 258-273.

[37] N. Sakai, T. Satoh, T. Kakuchi, Rod-like amphiphile of diblock polyisocyanate leading to cylindrical micelle and spherical vesicle in water, Macromolecules 47 (2014) 1699-1704.

[38] W. Vandesande, A. Persoons, The size and shape of macromolecular structures - determination of the radius, the length, and the persistence length of rodlike micelles of dodecyldimethylammonium chloride and bromide, J. Phys. Chem. 89 (1985) 404-406.

[39] E.C. Constable, W. Meier, C. Nardin, S. Mundwiler, Reversible metal-directed assembly of clusters of vesicles, Chem. Commun. (1999) 1483-1484.

[40] K. Matsuoka, A. Yonekawa, M. Ishii, C. Honda, K. Endo, Y. Moroi, Y. Abe, T. Tamura, Micellar size, shape and counterion binding of $\mathrm{N}$-(1,1-Dihydroperfluoroalkyl)-N, N,N-Trimethylammonium chloride in aqueous solutions, Colloid. Polym. Sci. 285 (2006) 323-330.

[41] P.A. Kralchevsky, K.D. Danov, S.E. Anachkov, G.S. Georgieva, K.P. Ananthapadmanabhan, Extension of the ladder model of self-assembly from cylindrical to disclike surfactant micelles, Curr. Opin. Colloid. Int. 18 (2013) 524-531.

[42] E. Johansson, A. Lundquist, S.S. Zuo, K. Edwards, Nanosized bilayer disks: attractive model membranes for drug partition studies, Bba-Biomembranes 1768 (2007) 1518-1525.

[43] F. Perrin, Mouvement Brownien d'un Ellipsoide (II). Rotation Libre Et Depolarisation des Fluorescences. Translation et Diffusion de Molecules Ellipsoidales, J. Phys. Radium 7 (1936) 11 